\title{
An experimental investigation on laser assisted waterjet microgrooving of GaAs wafer
}

\section{Lingyun Duan}

ChuanZhen Huang ( $\nabla$ huangcz7@163.com )

ShanDong University

Dun Liu

Peng Yao

Hanlian Liu

Xiaolan Bai

\section{Research Article}

Keywords: Laser assisted waterjet, Micromachining, GaAs wafer, Material removal

Posted Date: January 28th, 2022

DOI: https://doi.org/10.21203/rs.3.rs-1286442/v1

License: (c) (i) This work is licensed under a Creative Commons Attribution 4.0 International License. Read Full License 


\section{Abstract}

Gallium arsenide (GaAs), the most extensively used compound semiconductor material, has historically been difficult to manufacture in wafer fabrication due to its brittle property. A unique method called laser assisted waterjet (LAW) has been developed and utilized to micromachining brittle and fragile materials. The inclined waterjet expels the material heated and softened by the laser and aids in cooling to reduce thermal damage during the machining process. It has a lot of potential as a micromachining tool for GaAs wafers. In this study, microgrooves on GaAs wafers are machined using dry laser, low-pressure waterjet assisted laser (LWAL), and LAW technology. In comparison to dry laser and LWAL, LAW technology can process high-quality grooves with maximum depth, minimal thermal damage, and the maximum depth to width ratio, making it suitable for GaAs wafer micromachining. The mechanism for material removal in GaAs LAW processing is discussed, and it can be concluded that the majority of the material is removed by the impact of the high-pressure waterjet when it reaches the decomposition temperature below the melting point. A full-factorial experiment is carried out on GaAs wafers using LAW technology. The results show that six process parameters, including laser power, waterjet pressure, traverse speed, inclination angle, focal plane position, and processing times, have significant effects on groove depth, groove width, and material removal rate. The groove depth, groove width, and material removal rate is increased with an increase in term of laser power. More energy is wasted when the waterjet pressure is increased, resulting in a reduction in groove depth, groove width, and material removal rate.

\section{Introduction}

Gallium arsenide (GaAs) is the most extensively utilized compound semiconductor. Due to its high resistivity and electron mobility when compared to silicon, it is often used in the production of integrated circuit substrates, infrared detectors, microwave devices, and high-speed digital circuits. In the process of turning wafers into square chips, dicing is a necessary step. Chip performance is directly influenced by the wafer dicing process ${ }^{[1]}$.

GaAs wafers are now diced using ultra-thin diamond grinding ${ }^{[2-5]}$. The diamond grinding wheel blade is used to cut the wafer under the condition of steady and high-speed rotation. Due to the inherent mechanical strain in the dicing process, edge collapse, fissures, and other flaws will almost certainly occur, as would diamond tool wear. Furthermore, as the microelectronics sector expands, so does the demand for thin (less than $200 \mu \mathrm{m}$ ) wafer. The traditional dicing technique with a diamond grinding wheel is no longer feasible since GaAs is exceedingly brittle.

Laser ablation machining, which has been the focus of study in the field of wafer dicing, offers the advantages of high cutting precision, narrow slit, special-shaped cutting, and cutting tool saving when compared to mechanical grinding wheel machining ${ }^{[6,7]}$. Nevertheless, due to the splashing and deposition of molten materials, laser ablation will unavoidably cause thermal damage to the wafer surface and subsurface. The use of short-pulse laser, such as picosecond and femtosecond pulsed laser, 
or short wavelength laser, can reduce or even eliminate thermal damage, though the cost of the equipment climbs rapidly ${ }^{[8]}$. Wafer dicing has also been used in a number of non-traditional laser processing methods, including water guided laser, stealth laser, and laser thermal cleavage technology ${ }^{[9-}$ 13]. Water guided laser processing may efficiently reduce the heat affected zone (HAZ) and improve processing quality, but the equipment is complicated and costly. The stealth laser can only process materials that the laser can penetrate, necessitating the use of a split device that may readily shatter the wafer during the split process. The laser thermal cracking method has a wide heating range and is susceptible to wafer thermal damage.

A new hybrid laser-waterjet technology called laser assisted waterjet (LAW) was developed. The material is softened by nanosecond pulsed laser heating, and the softened material is removed and cooled by an angled high-pressure waterjet ${ }^{[14]}$. Using this method, a small HAZ on the specimen and a near-damagefree machined surface can be achieved. It has been demonstrated to be particularly suitable for the micromachining of hard and brittle materials, with results in microgroove machining of silicon, germanium, silicon carbide, and micro-milling of silicon nitride ceramics ${ }^{[14-17]}$. This processing technology is expected to be used for wafer dicing and etching, especially thin semiconductor wafer dicing. However, previous research has revealed that the processing parameters of this technique are dependent on the material being processed. As a result, this processing technology must be applied to other brittle and difficult-to-machine materials, such as GaAs. Hence, testing this technology on GaAs wafers and studying the effect of process parameters will aid in the implementation of this technology in the dicing of ultra-thin GaAs wafers.

In present study, comparative experiment among LAW technology, dry laser, and low-pressure waterjet assisted laser (LWAL) in micromachining GaAs was carried out with the goal of verifying the feasibility of processing GaAs wafers by LAW technology and investigating the material removal mechanism during the processing. Using full factor experiment, the effects of six essential LAW processing parameters on groove depth, groove width, and material removal rate were investigated.

\section{Experiment}

\subsection{Experiment apparatus and main parameters}

A nanosecond fiber laser generator with optical components, a pressurized air-driven waterjet pump, a precise motion control system, and a hybrid cutting head made up the experiment apparatus. The schematic of experimental setup is shown in Fig. 1. A random-polarized Gaussian beam with a wavelength of $1064 \mathrm{~nm}$, a pulse width of $200 \mathrm{~ns}$, a frequency of $100 \mathrm{kHz}$, and a maximum average power of $100 \mathrm{~W}$ was generated by the laser generator. A waterjet with a maximum pressure of $60 \mathrm{MPa}$ could be supplied by the waterjet pump. The hybrid cutting head was carried in a $300 \mathrm{~mm} \times 300 \mathrm{~mm}$ domain with $1 \mu \mathrm{m}$ sensitivity of the precise motion control system. 
The hybrid cutting head, as shown in Fig. 2a, was consisted by a laser head, an inclined waterjet nozzle, and a triaxial precision stage. The nozzle was fixed in the triaxial precision stage, which could adjust the inclination angle and position of the waterjet nozzle relative to the laser with an accuracy of $1 \mu \mathrm{m}$. The essential parameters in the machining process are shown in Fig. 2b. The laser beam had a focal diameter of $27.5 \mu \mathrm{m}$. The waterjet nozzle had a $300 \mu \mathrm{m}$ internal diameter. The distance between the focus plane and the workpiece surface is represented by the focal plane position ( $f p p)$. The focus was below the workpiece surface if the value was negative. According to their investigations, setting the target distance and waterjet offset distance to a fixed value of $1 \mathrm{~mm}$ and $0.5 \mathrm{~mm}$, respectively, was adequate. The detailed preset experimental parameters are listed in Table 1.

Table 1

Experimental condition and preset parameters

\begin{tabular}{|c|c|}
\hline Parameters & Values \\
\hline Laser wavelength & $1064 \mathrm{~nm}$ \\
\hline Laser frequency & $100 \mathrm{kHz}$ \\
\hline Pulse width & $200 \mathrm{~ns}$ \\
\hline Focal diameter & $27.5 \mu \mathrm{m}$ \\
\hline Nozzle inner diameter & $300 \mu \mathrm{m}$ \\
\hline Target distance & $1 \mathrm{~mm}$ \\
\hline Waterjet offset distance & $0.5 \mathrm{~mm}$ \\
\hline
\end{tabular}

Table 2

Physical properties of $\mathrm{GaAs}^{[18]}$

\begin{tabular}{|ll|}
\hline Characteristics & Values \\
\hline Mass density & $5.31 \mathrm{~g} / \mathrm{cm}^{3}$ \\
\hline Specific heat & $0.325 \mathrm{~J} /(\mathrm{g} \cdot \mathrm{K})$ \\
\hline Thermal conductivity & $0.425 \mathrm{~W} /(\mathrm{cm} \cdot \mathrm{K})$ \\
\hline Thermal diffusivity & $0.27 \mathrm{~cm}^{2} / \mathrm{s}$ \\
\hline Melting temperature & $1511 \mathrm{~K}$ \\
\hline Temperature of evaporation & $2628 \mathrm{~K}$ \\
\hline
\end{tabular}

\subsection{Material and experimental methodology}

The experiments were carried out on a GaAs wafer with a diameter of 2 in., a thickness of $350 \mu \mathrm{m}$, and a roughness of $0.5 \mathrm{~nm}$ on the workpiece surface. Table 2 lists the material's primary properties. The 
grooves were micromachined on the (100) crystallographic plane along the $<110>$ direction. Before groove processing, specimens were cleaned by ultrasonic in ethanol solution and deionized water for 15 minutes in sequence.

In this paper, the groove width, $\mathrm{W}$, groove depth, $\mathrm{H}$, and material removal rate, $v_{r}$ of the machined groove are investigated to assess the processing quality of the technology. For observation, a 3D laser microscope (Keyence VK-X200) is employed, which allows the groove depth and width to be measured directly. The machined V-shaped microgroove's cross-sectional area can be measured. Thus, the material removal rate can be calculated by

$$
V_{r}=A_{C} \cdot V
$$

Where, $v_{r} A_{C}$ and $v$ are material removal rate, cross-sectional area of groove, and traverse speed, respectively.

To investigate the effects of process parameters on the groove depth, groove width and material removal rate, six variable process parameters were employed, i.e. laser average power, $P_{l}$, waterjet pressure, $P_{w^{r}}$ traverse speed, $v$, inclination angle, $\theta$, focus plane position, $f_{p p^{\prime}}$ processing times, $\mathrm{n}$. To collect enough test data for an acceptable analysis, a full-factorial design method was used. However, six variables need far too many experiments. As a result, the number of tests should be limited, and the trials should be separated into two groups. Four levels of laser power, waterjet pressure, traverse speed, and inclination angle were employed in the first set, while a single level of fpp $(0 \mathrm{~mm})$, process times (1) was used in the second set. Table 3 shows the specific experimental design. The second set of tests looked at how fpp and process times affected groove depth and width, as shown in Table 4. The original material removal rate formula is no longer relevant when the process repetition is more than 1 , the effects on material removal rate are only explored when the process times is the value of 1 .

Thus, there were 320 tests in total (256 in the first set and 64 in the second set) to offer enough data for investigation. Three measurements of each machined groove geometry, including groove depth, groove width and cross-sectional area, were taken and averaged for the final reading

In addition, with the parameter settings specified in Table 5, comparative experiment of LAW, dry laser ablation, and LWAL was performed. The conditions of other experimental parameters not mentioned are the same as those mentioned in Table 1. 
Table 3

Parameters used in the first set of experiment

\begin{tabular}{|lllll|}
\hline Factors & \multicolumn{3}{l}{ Level } \\
\cline { 2 - 6 } & $\mathbf{1}$ & $\mathbf{2}$ & $\mathbf{3}$ & $\mathbf{4}$ \\
\hline Laser power, $P_{(}(\mathrm{W})$ & 12 & 15 & 18 & 21 \\
\hline Waterjet pressure, $P_{W}(\mathrm{MPa})$ & 4 & 7 & 10 & 13 \\
\hline Traverse speed, $\mathrm{v}(\mathrm{mm} / \mathrm{s})$ & 4 & 8 & 12 & 16 \\
\hline Inclination angle, $\theta(\mathrm{deg})$ & 40 & 44 & 48 & 52 \\
\hline Focus plane position, $f_{p p}(\mathrm{~mm})$ & 0 & & & \\
\hline Processing times, $\mathrm{n}$ & 1 & & & \\
\hline
\end{tabular}

Table 4

Parameters used in the second set of experiments

\begin{tabular}{|lllll|}
\hline Factors & \multicolumn{4}{l|}{ Level } \\
\cline { 2 - 5 } & $\mathbf{1}$ & $\mathbf{2}$ & $\mathbf{3}$ & $\mathbf{4}$ \\
\hline Laser power, $P_{I}(\mathrm{~W})$ & 12 & 21 & & \\
\hline Waterjet pressure, $P_{W}(\mathrm{MPa})$ & 4 & 13 & & \\
\hline Traverse speed, $\mathrm{v}(\mathrm{mm} / \mathrm{s})$ & 4 & & & \\
\hline Inclination angle, $\theta(\mathrm{deg})$ & 44 & & & \\
\hline Focus plane position, $f_{p p}(\mathrm{~mm})$ & 0 & -0.1 & -0.2 & -0.3 \\
\hline Processing times, $\mathrm{n}$ & 1 & 2 & 3 & 4 \\
\hline
\end{tabular}


Table 5

Process parameters used in the comparative experiments

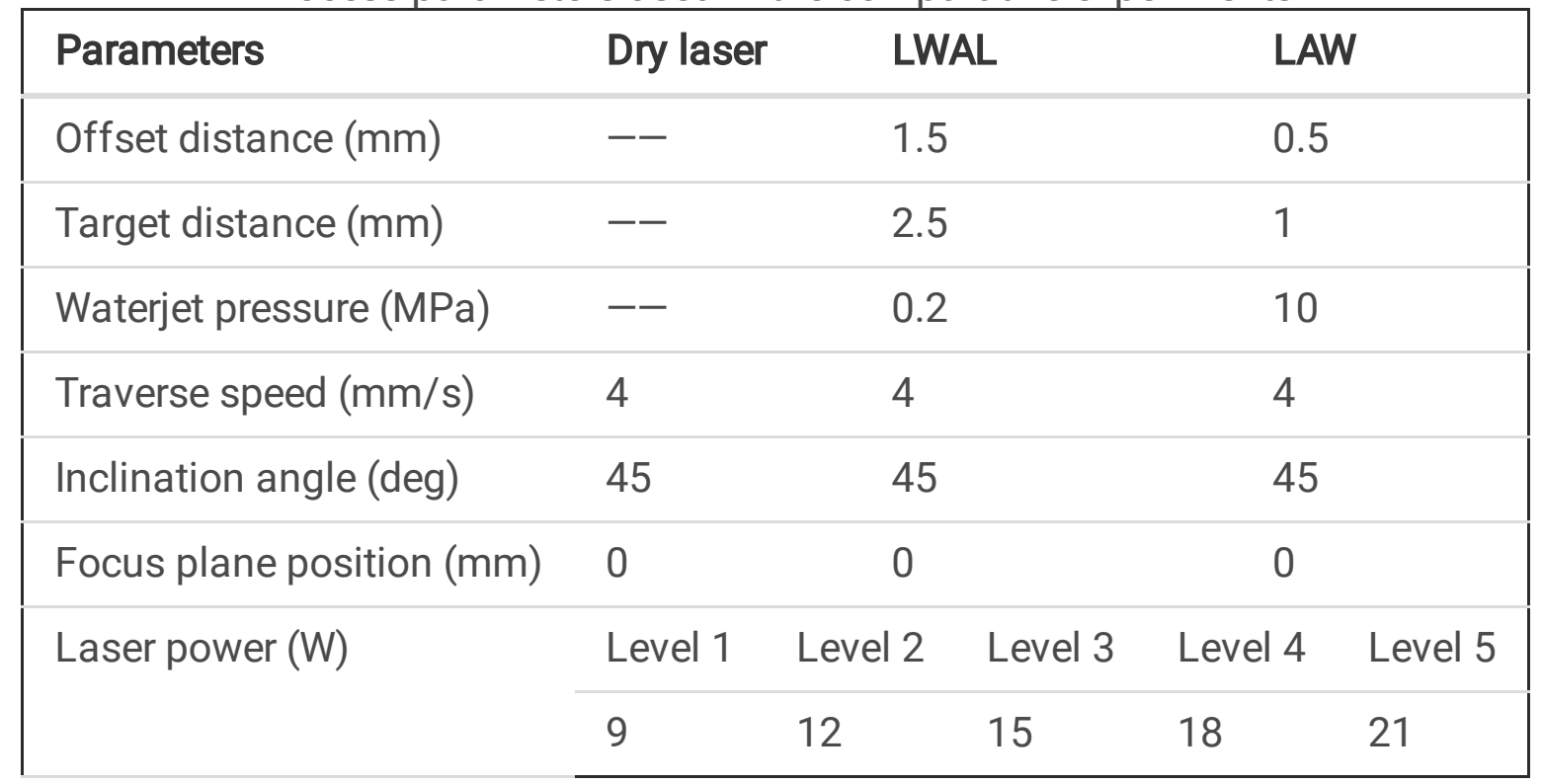

\section{Results And Discussion}

\subsection{Comparative experiment}

At a laser power of $15 \mathrm{~W}$, Fig. 3 depicts the profile of the grooves machined by the three processing methods in the comparative experiment. In Fig. 3a, there is no auxiliary gas used in dry laser ablation, the material is fully removed by the laser thermal effect. From the top view, the color on both sides of the groove changes significantly, indicating the formation of a HAZ on both sides of the notch. The raw surface has black patches, suggesting that the temperature of the material after laser heating is substantially higher than the melting point of material $1511 \mathrm{~K}$. The overheated molten substance splashes and redeposits on the surface of the material, resulting in apparent contamination. The groove's 3D shape and cross-sectional profile are both of poor quality. On both sides of the groove, there are evident discontinuous protrusions. The profile is M-shaped in cross-section. In relation to the unmachined surface, the horizontal height of the highest point of the protrusions on both sides of the M-shaped is $6.195 \mu \mathrm{m}$. The measured value for the groove bottom is $4.729 \mu \mathrm{m}$, which is slightly lower than the raw surface.

In Fig. 3b, low-pressure waterjet is used to clean and cool workpiece during laser processing. The molten material generated by laser heating is either instantly cooled and solidified on the groove surface, or it is hardened into solid particles and carried away by flowing water. As shown in top view, on the surface near the machining groove, there is essentially no pollution caused by molten particles, but the edge of the cutting is irregular. The groove's 3D shape and profile quality are superior to dry laser cutting. At the groove's edge, the bulge caused by the cooling and solidification of molten materials can be seen. The groove has a wide V-shaped cross-sectional profile, and there are still bulges on both sides created by heating. $4.576 \mu \mathrm{m}$ is the horizontal height of the bulge's highest point in relation to the raw surface. The 
groove bottom is $20.553 \mu \mathrm{m}$ deep in relation to the raw surface. When compared to dry laser cutting, the groove depth increases dramatically.

As shown in Fig. 3c, the high-pressure waterjet is used to remove and cool material during the LAW machining process. The unprocessed surface surrounding the processed groove is clean, the groove's edge is straight, and no HAZ is visible. The quality of the processing is clearly superior to that of dry laser ablation and LWAL processing. The transition between the groove and the unmachined surface is smooth, and there is no bulge owing to heat effects, according to the groove's cross-sectional profile. As shown in Fig. 4, the section profile obtained by LAW is compared to that obtained by dry laser and LWAL at the laser power of $15 \mathrm{~W}$. The processed groove has the greatest depth and the lowest processing width which includes HAZ width, with values of $68.946 \mu \mathrm{m}$ and $56.820 \mu \mathrm{m}$, respectively.

The width of the HAZ can be used to evaluate the degree of thermal damage to the material caused by laser heat, and the depth to width ratio of the machined grooves can be used to test the ability of the processing technology to process small seams or grooves. Under three different processing settings, Fig. 5 depicts the influence of laser power on the width of the HAZ and the depth to width ratio of microgrooves. The width of the HAZ of the grooves processed by the LAW technique is the lowest and rises with increasing laser power. Furthermore, the depth to width ratio of grooves processed by LAW is similar to that of LWAL and dry laser processing at lower power, but it increases dramatically as laser power grows. Therefore, in comparison to the other two processing methods, the LAW technology processes grooves with the least thermal damage and the highest depth to width ratio.

Figure 6 shows SEM images of microgrooves machined by the three machining methods at a power level of 21 W. As shown in Fig. 6a, the groove surface obtained by dry laser ablation has obvious melting and recast characteristics, a large amount of lumpy and granular residue accumulation, the formation of obvious large holes in the groove, and the presence of obvious micro-cracks caused by thermal stress on the groove surface. This is because the thermal effect of the laser during the dry laser processing of GaAs wafers causes the principal removal method, GaAs melting, which is accompanied by thermal decomposition ${ }^{[19,20]}$.

In Fig. 6b, the material on groove surface is not homogeneous and contains a large number of conical bumps as a result of LWAL processing. On the stacked material, there are many microscopic pores, which are small holes left by the breakdown process of GaAs material at high temperatures and the escape of arsenic vapor. During the processing, the low-pressure waterjet cools the thermal breakdown products and removes some of them.

In Fig. 6c, the groove surface is uniformly distributed with no substantial material build-up using the LAW machining technology. There is still a well-defined HAZ at the groove's top boundary. In addition, there is a visible continuous crack continuing along the machining direction at the bottom of the groove. There could be two reasons for this. On the one hand, the high temperature in the laser center, with the high laser power of $21 \mathrm{~W}$, causes thermal stress, resulting in this condition. On the other hand, GaAs is 
extremely fragile. The increased Reynolds number of the waterjet at the bottom region causes a distinct periodic undulation at the bottom of the groove, resulting in an unstable impact action.

Three sample regions are chosen in Fig. $6 \mathrm{c}$. The HAZ is I, the groove's side is II, and the groove's bottom is III. These three regions' elemental compositions were investigated using EDS. Table 6 displays the weight percentages of each element for the material's unmachined surface as well as the three cutting groove regions. When compared to the original material surface, there is little change in the elemental weight percentage in region $\mathrm{I}$, or $\mathrm{HAZ}$, as shown in Table 6 , although a trace quantity of 0 element occurs. Once the decomposition temperature $(900 \mathrm{~K})$ is achieved, the GaAs material decomposes into arsenic and gallium, with the arsenic evaporating from the surface and the metallic gallium producing oxide layers. This implies that on the HAZ surface, a minor thermal decomposition occurred, resulting in a decrease in As content. The majority of the decomposition products are removed by the waterjet and trace amounts of metallic Ga collecting oxygen from the air to produce oxides. The reduction of As elements in the groove wall (region II) and groove bottom (region III), as well as the absence of oxygen elements, indicate that the material undergoes thermal decomposition during processing, and As elements sublimate and are removed with the waterjet, with some metal Ga adhering to the cut groove side walls. Due to the impact of the waterjet, the decomposition products at the groove's bottom are more fully eliminated.

Table 6

The weight percent of elemental contents in raw surface and different regions

\begin{tabular}{|lllll|}
\hline Region & As/\% & Ga/\% & O/\% & Total/\% \\
\hline Raw surface & 52.6 & 47.4 & & 100 \\
I & 50.5 & 46.8 & 2.7 & 100 \\
II & 44.3 & 55.7 & & 100 \\
\hline III & 51.9 & 48.1 & & 100 \\
\hline
\end{tabular}

During dry laser processing, the material temperature above the melting point is removed by an air jet, and during LWAL technology processing, the molten material is removed by running water. The principle of gallium arsenide removal using LAW technology is not the same as these two. The temperature gradient in the LAW technology process is modest because to the small absorption coefficient of GaAs to $1064 \mathrm{~nm}$ wavelength laser ${ }^{[18]}$. Except for the melting in the laser center's high-temperature area, the majority of the material is removed by the impact of a high-pressure waterjet after reaching the decomposition temperature but not the melting point, effectively reducing the thermal damage of GaAs to the highly brittle material caused by the laser thermal effect. Nevertheless, further numerical simulation or theoretical research on the temperature and stress fields in the processing of GaAs materials is required to determine the precise removal mechanism.

The above comparison test results and analyses reveal that the LAW method can produce high-quality micro-grooves on GaAs wafers with tiny groove widths, large groove depths, and minimal thermal damage, making it ideal for GaAs microfabrication. 


\subsection{Effect of processing parameters on groove depth}

Fig. 7 depicts the effect of waterjet pressure on the microgroove depth of GaAs wafer processing. With increasing waterjet pressure, the groove depth diminishes. The material softened by laser can be removed more quickly as the water pressure is increased. Increased water pressure, on the other hand, raises the Reynolds number of the flowing water layer, increases the convective heat transfer coefficient between the waterjet and the material, and improves cooling. Because the cooling effect of the waterjet on material removal is greater than the cooling effect of the waterjet on material removal, the groove depth reduces when the waterjet pressure is increased. Fig. 8 shows the 3D profile of grooves at an $18 \mathrm{~W}$ laser power level. In the picture, although the groove depth reduces slightly as the waterjet pressure is increased, there is no substantial material build-up in the microgroove grooves created under higher pressure circumstances, and the machining quality is improved.

The influence of average laser power on groove depth is shown in Fig. 7a. When all other parameters stay constant, increasing laser power increases the energy of a single laser pulse, making the heating area deeper in the depth direction and softening more materials, resulting in a deeper groove. Fig. 9 depicts the $3 \mathrm{D}$ contours of the grooves machined at various laser power settings with a $10 \mathrm{MPa}$ waterjet pressure.

The groove depth grows as the laser power increases, however the quality of the groove obtained at $21 \mathrm{~W}$ is not very good, as shown in Fig. 9d, implying that higher power must be combined with higher waterjet pressure to achieve good surface quality.

Figure $7 \mathrm{~b}$ depicts the influence of waterjet inclination angle on groove depth, demonstrating that as the waterjet inclination angle increases, the groove depth decreases. This is because the larger the waterjet's inclination angle, the thicker the water film transmitted by the laser, resulting in more laser energy loss. The waterjet impact force in the groove depth direction decreases simultaneously, and finally, a smaller groove depth is obtained.

The influence of traverse speed on groove depth is seen in Fig. 7b. At low speeds, it is evident that deeper grooves can be obtained. The rationale is the same as the effect of laser energy on groove depth. Any spot on the groove will receive more laser pulses at low speeds. The materials degraded or softened in the pulse gap will be eliminated by waterjet impact after a pulse laser has been heated. The groove depth will grow as additional pulses are processed repeatedly.

The effect of fpp on the groove depth is shown in Fig. 7c. When the laser focal point is just above the material surface, the highest groove depth is achieved. As the laser focus plane travels down, the groove depth diminishes. This is because, the lower the focal plane, the larger the volume of the overlapping circular platform between the laser beam and the waterjet. The laser will pass through more water with a lower density, causing significant energy loss. Therefore, the lower the focal plane, the smaller the groove depth.

Figure 7c illustrates that at low power, the loss in cutting groove depth is not noticeable, but at high power, it is. This is because the groove depth obtained at high power is greater, which means the laser 
must penetrate a greater volume of water to radiate to the material surface, and the proportion of laser energy wasted is greater, resulting in a greater reduction in groove depth.

The effect of processing times on groove depth is seen in Fig. 7d. Displayed effect patterns differ at high and low power conditions. The processing depth increases slightly with the processing times at low power. It is because the depth of the first processing groove is shallow. In the subsequent multiple processing processes, the volume of water transmitted by the laser is small and the energy loss is small, and laser energy is still working on the material surface. Fig. 10 depicts the change in groove profile caused by multiple processing at high power $21 \mathrm{~W}$ and high waterjet pressure $13 \mathrm{MPa}$. Even after the energy loss in the second processing, the energy reaching the material surface at high power is sufficient, and the groove depth grows significantly after heating and melting removal. The material on the bottom sidewall of the groove will be softened and extruded to the bottom of the groove under the action of the waterjet during the third and fourth processing pass, as the groove is already deep and the heating radius of the unfocused laser is large, and the cross-section of the groove will change from a deep V-shape to a V-shape with a larger opening kerf, and the depth of the groove will decrease.

\subsection{Effect of processing parameters on groove width}

Figure 11a depicts the effect of the waterjet pressure on groove width. The effect of waterjet pressure on groove width is not readily apparent. Because the cooling effect of the waterjet is strengthened as waterjet pressure is increased, the width of the heating area of laser heat along the groove width direction shrinks to some extent, resulting in a smaller groove width. However, increasing the waterjet pressure increases the shear force of the waterjet on the material softened by laser heating, hence increasing the removal impact of the waterjet on the material, resulting in a wider groove width. Finally, because the cooling impact is slightly greater than the removal effect, the groove width narrows slightly as waterjet pressure is increased.

The influence of laser power on groove width is shown in Fig. 11a. The width of the groove is increased as the laser power is increased. This is because a higher laser power causes the heated zone of the material to be wider in the breadth direction, resulting in wider machined grooves. As shown in Fig. 12, higher laser power processing at $4 \mathrm{MPa}$ and $13 \mathrm{MPa}$ waterjet pressure, respectively, both yielded wider grooves.

The effect of the waterjet inclination angle on the cutting width is shown in Fig. 11b. The width of the cutting groove is unaffected by the inclination angle of the waterjet. On the one hand, the energy distribution of the pulsed laser has a significant impact on the width of the microgroove. The increase in water film thickness caused by the change in inclination angle will increase laser energy loss and diminish the breadth of the laser high energy zone in the groove width direction. On the other hand, as the inclination angle increases, the waterjet impact force in the vertical direction decreases, the horizontal direction increases, and thus the parallel to the workpiece surface shear force increases, the softened material is removed more easily, and the groove width increases. In short, the increase in waterjet 
inclination angle almost has no effect on groove width due to the combined effect of increasing laser energy loss and waterjet shear force.

The effect of processing speed on groove width is shown in Fig. 11b. The groove width does not change significantly because the processing speed cannot modify the energy distribution of the laser in the groove width direction. As seen in Fig. 13, the edge boundary of the groove created by processing is clear at slower processing speeds. The groove border is ragged at higher processing speeds, such as $16 \mathrm{~mm} / \mathrm{s}$, although the overall groove curvature is owing to the equipment's lower accuracy at higher processing speeds.

At low and high laser power, the width of the microgroove in proportion to the fpp differs in Fig. 11c. When the focus point is immediately below the material surface, the spot diameter is the smallest, and the groove width obtained after processing on the material surface is also the lowest, so the groove width increases somewhat with the downward movement of the focal plane location. The spot diameter is larger and the groove width is likewise larger in the situation of negative focal plane, or when the focal point is below the material surface. The effect of high power on groove width is substantially bigger than the effect of changing focal plane position when using high power. As a result, in the condition of high power, the groove width remains nearly unchanged.

The effect of processing times on groove width is seen in Fig. 11d. Because the heat generated by the thermal action of the laser is passed from the bottom of the groove to the side wall of the groove during the process of laser multiple processing, the surface of the side wall material softens and is removed by waterjet shearing, increasing the groove width. Fig. 10 depicts the groove profile at various machining times, demonstrating that the groove width grows as the processing times rises.

\subsection{Effect of processing parameters on material removal rate}

Figure 14a depicts the impact of waterjet pressure on the rate of material removal. Because increasing the waterjet pressure reduces the groove width and depth, the cross-sectional removal area of the groove decreases. The relationship between laser power and material removal rate is shown in Figure 14a. At high laser power, it is evident that a higher material removal rate is obtained, which is also attributable to an increase in the width and depth of the groove, as well as the cross-sectional area of the groove, resulting in a higher material removal rate.

The effect of the waterjet inclination angle on the material removal rate is shown in Fig. 14b. Because the waterjet inclination angle has little effect on groove width, the trend conforms to the inclination angle's effect on groove depth, i.e., the material removal rate falls as the waterjet inclination angle increases.

Figure 14b shows how machining speed affects the rate of material removal. As can be seen, the higher the processing speed, the greater the material removal rate. This is because, during processing, the traverse speed only affects the overlap rate of the laser pulses, not the energy of the individual pulses. 
Although the faster processing speed reduces the depth of the machined groove, the groove depth is lowered slightly, as shown in Fig. 7c, while the groove width is practically unaltered, resulting in a smaller drop in the cut groove's cross-sectional area. The material removal rate, on the other hand, is the product of the cross-sectional area and the machining speed, so the material removal rate increases as the material is machined at a faster traverse speed.

The influence of the laser fpp on the rate of material removal is shown in Fig. 14c. Its influence on the removal rate is consistent with the effect of the fpp on the groove depth, because the focal plane position has little effect on the groove width. In low power laser level, the lower the laser fpp, the slower the removal rate falls. The material removal rate falls noticeably when high laser power is used.

\section{Conclusions}

In this paper, comparison study on dry laser, LWAL, and LAW technologies was carried out on GaAs wafer. The effects of six essential parameters, i.e. laser power, waterjet pressure, traverse speed, inclination angle, focal plane position, and processing times, of the LAW technology on the groove depth, groove width, and material removal rate were investigated by full factorial experiment on GaAs wafers. The following conclusions were reached:

1. According to the results of comparison experiment, the LAW processing method is ideally suitable for the processing of GaAs materials. It enables the production of high-quality grooves with the deepest depth, a contamination-free wafer surface, minimal thermal damage, and the largest depth to width ratio.

2. The grooves obtained by the three processing methods were studied using SEM, and the groove obtained by the LAW technology was analyzed using EDS. The results show that the LAW technique produces almost no thermal damage on the surface of the grooves. The material is softened and decomposed by laser heating when it reaches the decomposition temperature, and that the softened material and decomposition products are removed by high-pressure waterjet.

3. The impacts of LAW processing parameters on the depth and width of the microgroove after cutting, as well as the material removal rate, are investigated and analyzed. The groove depth increases as the laser power increases, and reduces as the waterjet pressure, inclination angle, and processing speed increases. It lowers as the laser fpp shifts downward. It's noted that the groove depth does not always rise as the processes time increases. The groove depth achieves the maximum groove depth for the second time at high laser power, and thereafter the groove depth falls as the number of processes increases. Groove width is primarily affected by laser power and processing time, with other variables having minor impact. The material removal rate increases dramatically as laser power and processing speed rise, but reduces as waterjet pressure and inclination angle rise, with the former having a smaller influence. At high laser power levels, the material removal rate falls as the laser focus plane moves downward, but not much at low laser power levels. 
This research paves the way for future research into the material removal process caused by the interaction between laser heating and waterjet cooling, as well as the use of this technology to wafer dicing.

\section{Declarations}

Author contribution Lingyun Duan: investigation and writing; Chuanzhen Huang: review and editing; Dun

Liu: advice and guidance; Peng Yao: advice and guidance; Hanlian Liu: advice and guidance; Xiaolan Bai: review.

Funding This work is financially supported by Independent Training and Innovation Team Project of Jinan Science and Technology Bureau [NO.2019GXRC009], Major Program of Shandong Province Natural Science Foundation [NO.ZR2018ZA0401], and National Natural Science Foundation of China [N0.52075300].

Availability of data and material The data and material during the study are listed in this paper.

Ethics approval Not applicable.

Consent to participate Yes.

Consent for publication Yes.

Conflict of interest The authors declare no competing interests.

\section{References}

1. Brown W (2009) Introduction and Overview of Microelectronics Packaging. Advanced Electronic Packaging:With Emphasis on Multichip Modules

2. Kim SC, Lee ES, Kim NH, Jeong HD (2007) Machining characteristics on the ultra-precision dicing of silicon wafer. Int J Adv Manuf Technol 33(7-8):662-667

3. Chen S, Tsai CZ, Wu E, Shih IG, Chen YN (2006) Study on the Effects of Wafer Thinning and Dicing on Chip Strength. IEEE Trans Adv Packag 29(1):149-157

4. Wei-Sheng Lei AK (2012) and Rao Yalamanchili Die singulation technologies for advanced packaging A critical review.Journal of Vacuum Science \& Technology B.

5. Luo SY, Wang ZW (2008) Studies of chipping mechanisms for dicing silicon wafers. Int J Adv Manuf Technol 35(11-12):1206-1218

6. Molian P, Pecholt B, Gupta S (2009) Picosecond pulsed laser ablation and micromachining of $4 \mathrm{H}-\mathrm{SiC}$ wafers. Appl Surf Sci 255(8):4515-4520

7. Saurabh G, Ben P, Pal M (2011) Excimer laser ablation of single crystal $4 \mathrm{H}-\mathrm{SiC}$ and $6 \mathrm{H}-\mathrm{SiC}$ wafers. J Mater Sci 46(1):196-206 
8. Fornaroli C, Holtkamp J, Gillner A (2013) Dicing of Thin Si Wafers with a Picosecond Laser Ablation Process. Physics Procedia 41(Complete):603-609

9. Dushkina NM, Wagner FR, Boillat C, Buchilly JM, Richerzhagen B (eds) (2003) Water jet guided laser versus saw dicing. Lase

10. Uchiyama N (2012) Stealth Dicing Technology. Journal of the Society of Mechanical Engineers 115(1126):644-645

11. Kumagai M, Uchiyama N, Ohmura E, Sugiura R, Fukumitsu K (2007) Advanced Dicing Technology for Semiconductor Wafer-Stealth Dicing. IEEE Trans Semicond Manuf 20(3):259-265

12. Takeda R, Ueda T, Furumoto T, Hosokawa A, Tanaka R Study on Cleaving Mechanism of Silicon Wafer by Laser Beam Irradiation. Proceedings of International Conference on Leading Edge Manufacturing in 21st century LEM21. 2009;2009.5

13. Haupt O, Siegel F, Schoonderbeek A, Richter L, Ostendorf A (2008) Laser Dicing of Silicon: Comparison of Ablation Mechanisms with a Novel Technology of Thermally Induced Stress.Journal of Laser Micro Nanoengineering. ; 3(3)

14. Tangwarodomnukun V, Wang J, Huang CZ, Zhu HT (2012) An investigation of hybrid laser-waterjet ablation of silicon substrates. Int J Mach Tools Manuf 56(none):39-49

15. A HZ, A JW BPY (2017) Heat transfer and material ablation in hybrid laser-waterjet microgrooving of single crystalline germanium. Int J Mach Tools Manuf 116:25-39

16. Feng S, Huang C, Wang J, Zhu H (2018) Material removal of single crystal $4 \mathrm{H}-\mathrm{SiC}$ wafers in hybrid laser-waterjet micromachining process. Materials ence in Semiconductor Processing 82:112-125

17. Wang L, Huang C, Wang J, Zhu H, Liang X (2017) An experimental investigation on laser assisted waterjet micro-milling of silicon nitride ceramics.Ceramics International. :S027288421732922X

18. Da Chi A (1990) S. Properties of GaAs.

19. Qi H, Wang Q, Zhang X, Liu Z, Liu Z, Chang J et al (2008) Investigation on damage process of GaAs induced by $1064 \mathrm{~nm}$ continuous laser. J Appl Phys 103(3):3399

20. Qj H, Wang Q, Zhang X, Liu Z, Zhang S, Chang J et al (2011) Theoretical and experimental study of laser induced damage on GaAs by nanosecond pulsed irradiation. Optics \& Lasers in Engineering 49(2):285-291

\section{Figures}




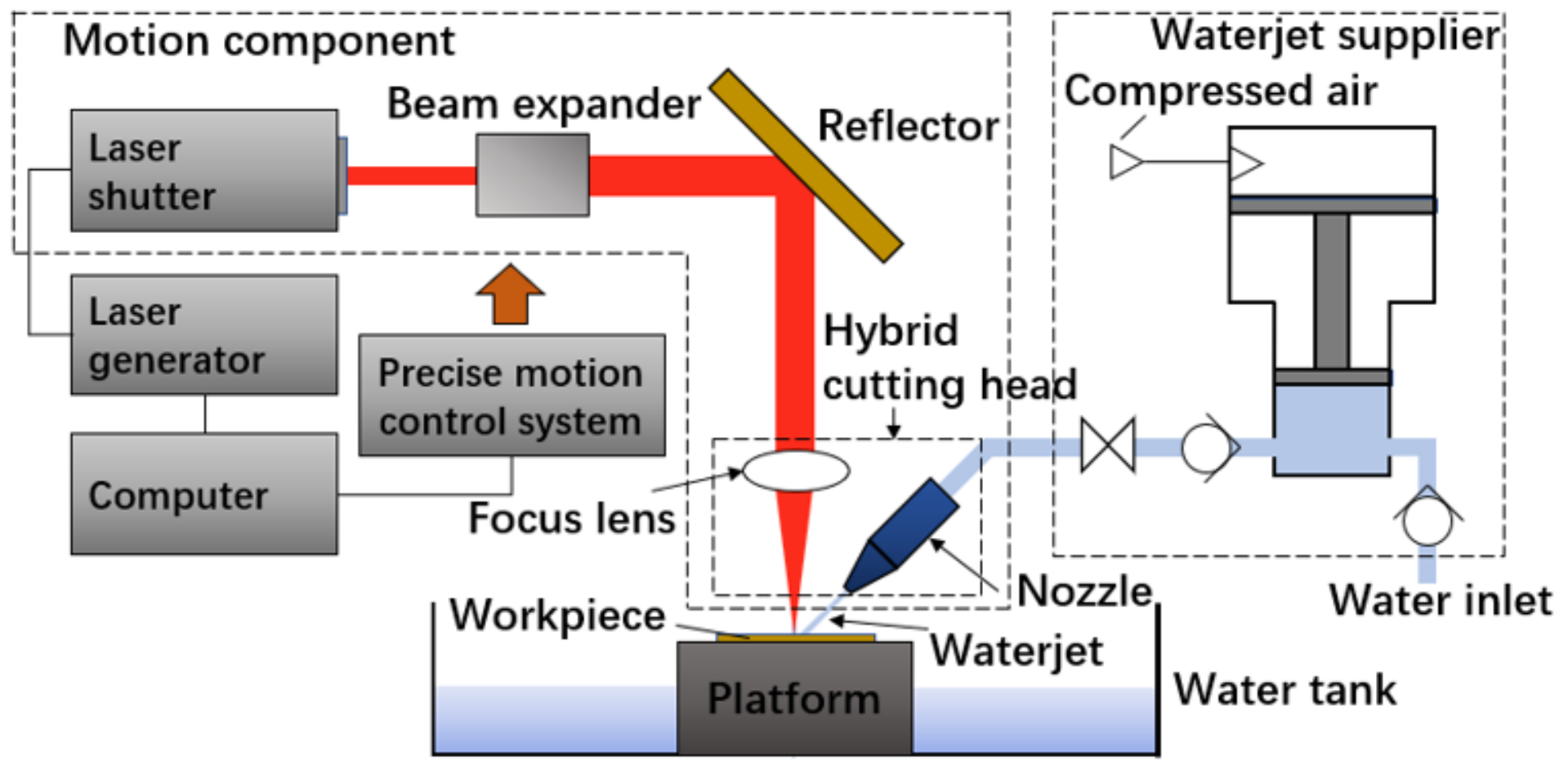

Figure 1

Schematic of experimental setup

(a)

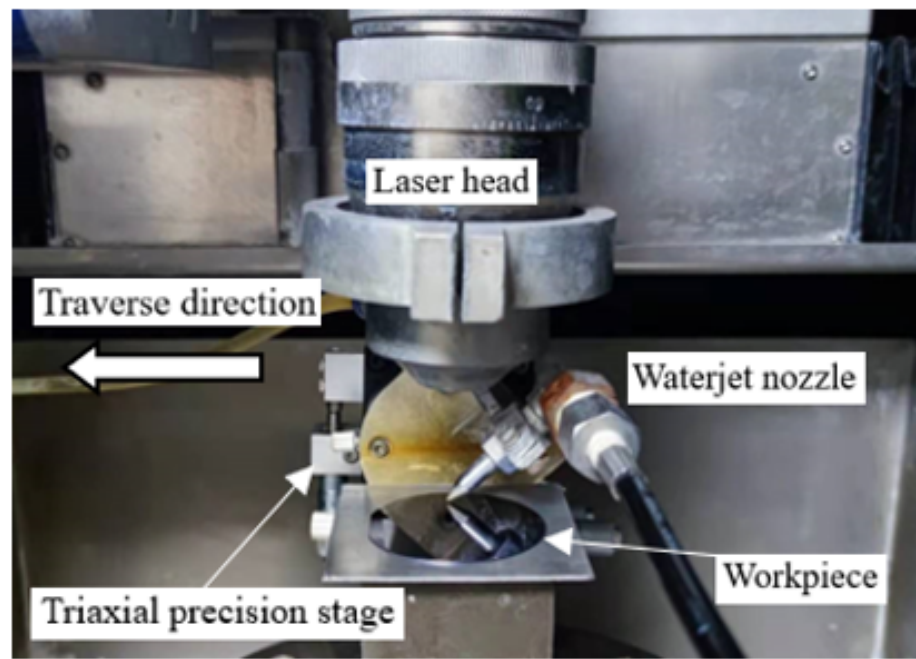

(b)



Figure 2

Hybrid cutting head and essential parameters. a hybrid cutting head, $\mathbf{b}$ essential parameters of hybrid cutting head 
(a)

$$
\begin{aligned}
& 300 \\
& 200 \\
& 150 \\
& 100 \\
& 50
\end{aligned}
$$

500. 703. 6 (b)

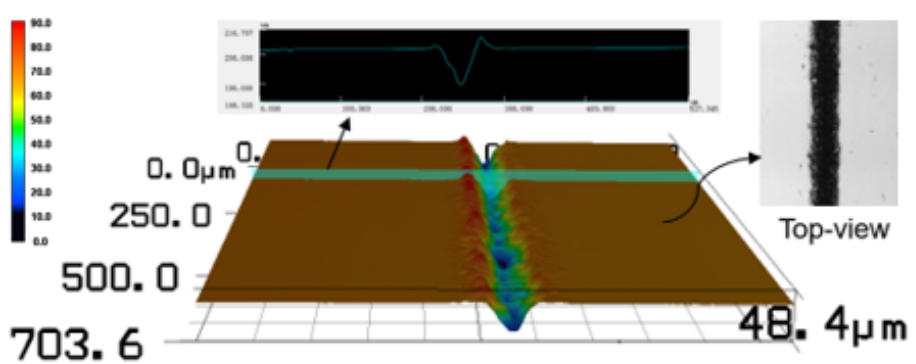

(c)

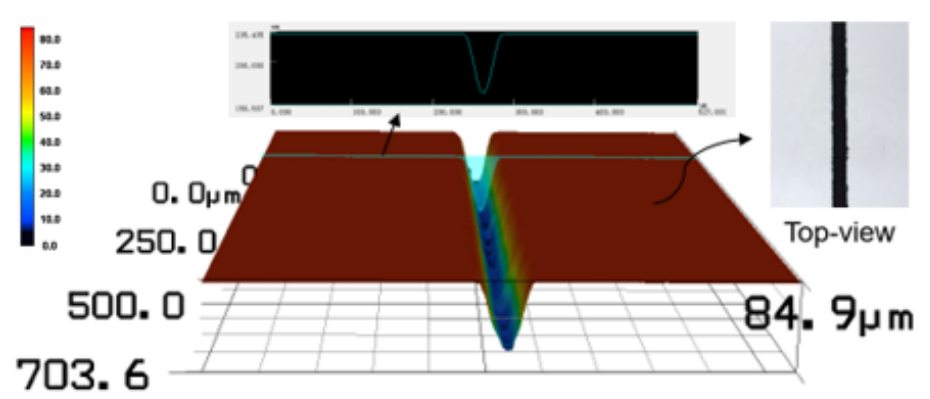

\section{Figure 3}

Microgroove processed by different technologies. a dry laser micromachining with laser power $15 \mathrm{~W}, \mathbf{b}$ LWAL micromachining with laser power $15 \mathrm{~W}$, offset distance $1.5 \mathrm{~mm}$, target distance $2.5 \mathrm{~mm}$, waterjet pressure $0.2 \mathrm{MPa}, \mathrm{c}$ LAW micromachining with laser power $15 \mathrm{~W}$, offset distance $0.5 \mathrm{~mm}$, target distance $1 \mathrm{~mm}$, waterjet pressure $10 \mathrm{MPa}$ 


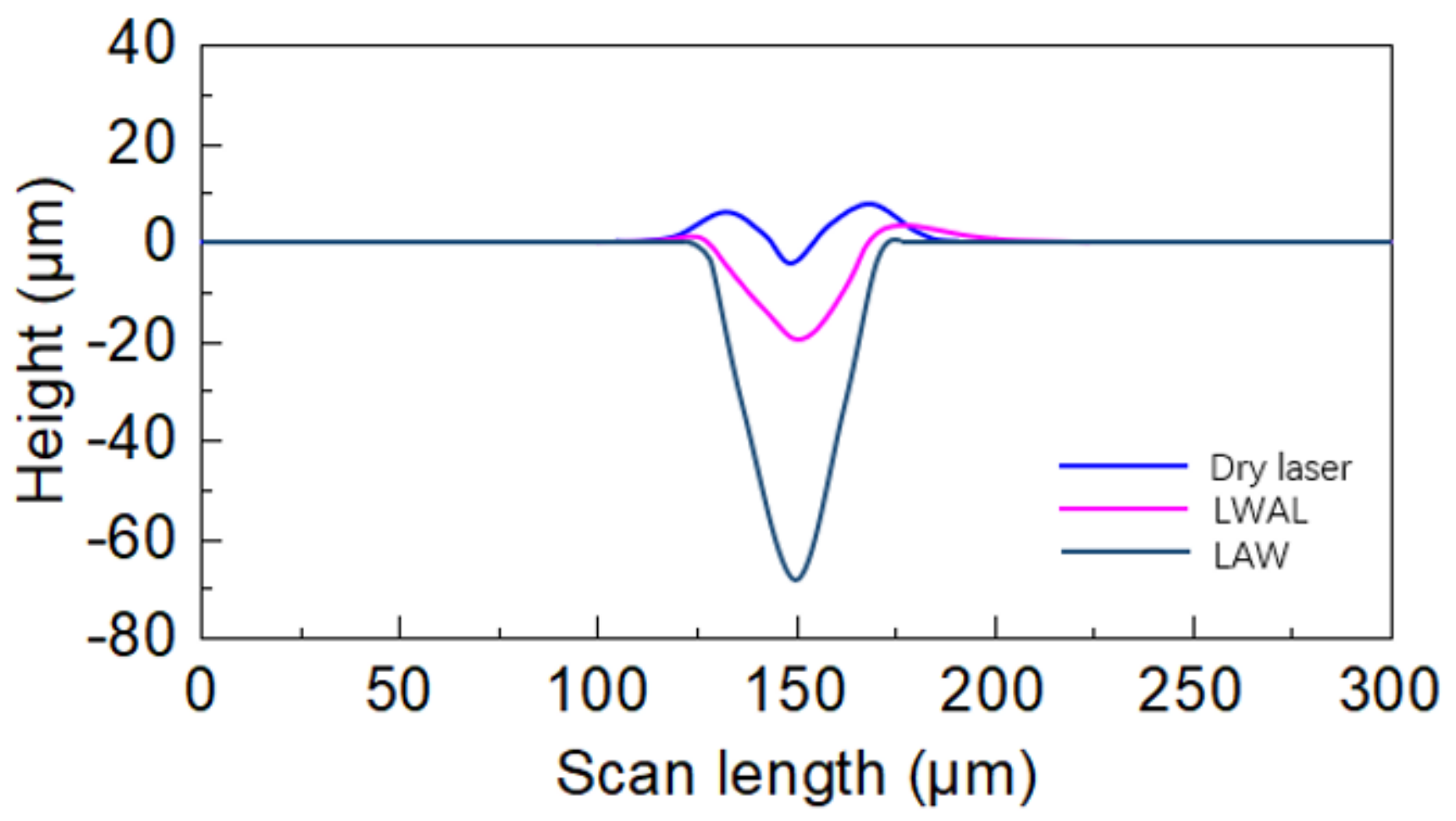

Figure 4

Cross-sectional profiles of grooves obtained by dry laser, LWAL, and LAW with laser power $15 \mathrm{~W}$

(a)

(b)
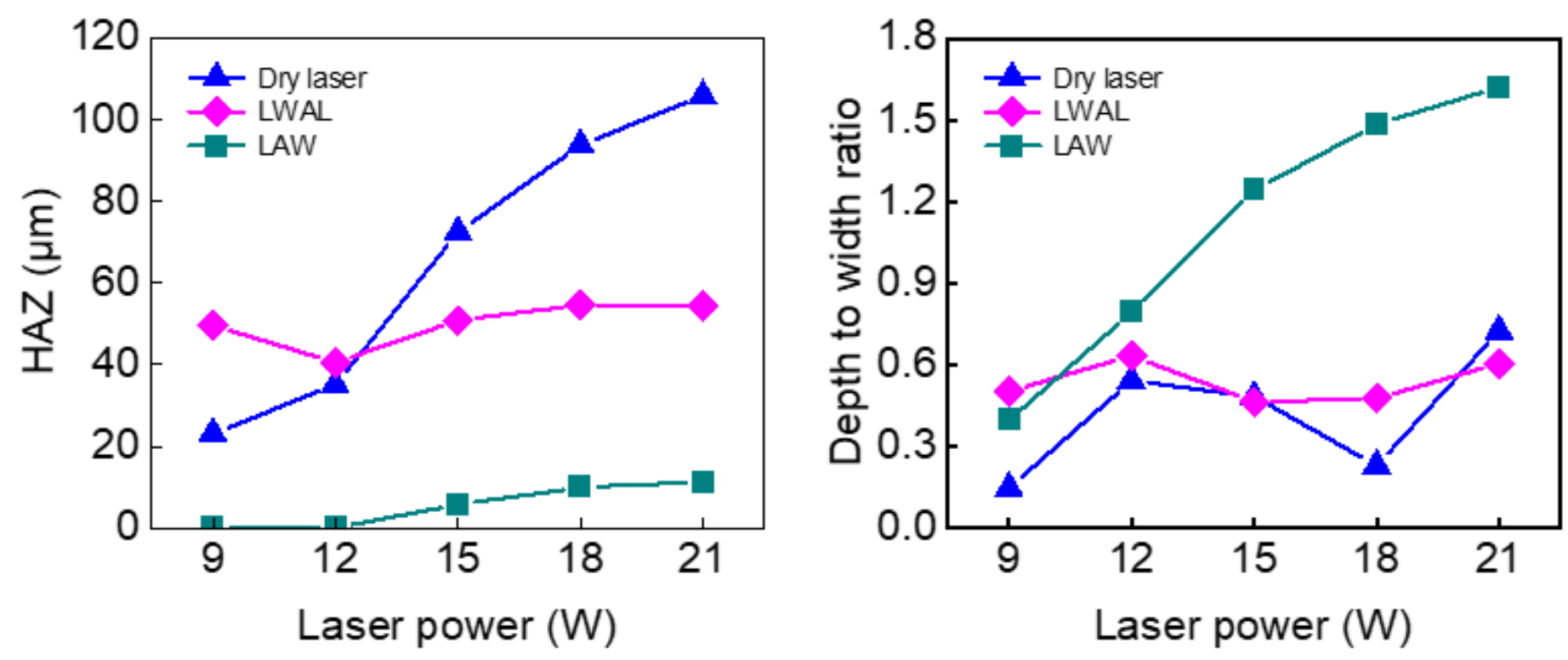

Figure 5 
Effect of laser power on HAZ and depth to width ratio by different processing methods. a Effect of laser power on HAZ, b Effect of laser power on depth to width ratio

(a)


(c)

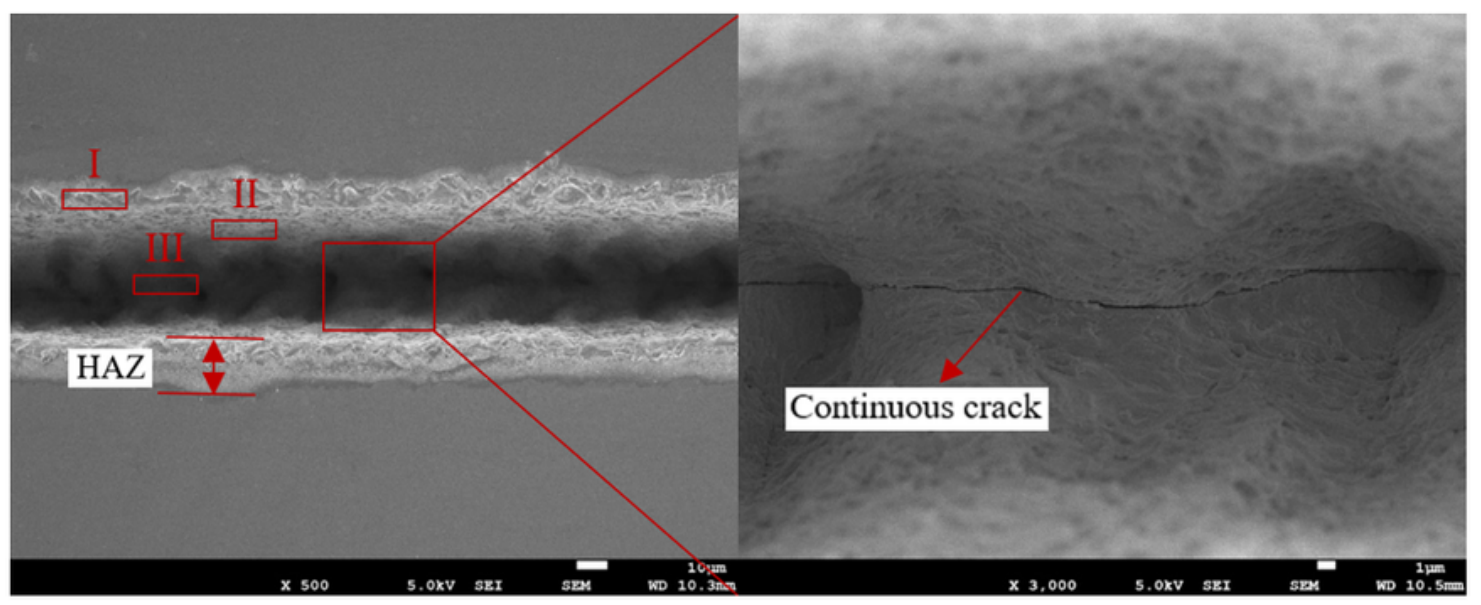

Figure 6 
SEM images of machined grooves of GaAs wafer by dry laser, LWAL and LAW. a dry laser micromachining with laser power $21 \mathrm{~W}$, b LWAL micromachining with laser power $21 \mathrm{~W}$, offset distance $1.5 \mathrm{~mm}$, target distance $2.5 \mathrm{~mm}$, waterjet pressure $0.2 \mathrm{MPa}, \mathrm{c}$ LAW micromachining with laser power 21 $\mathrm{W}$, offset distance $0.5 \mathrm{~mm}$, target distance $1 \mathrm{~mm}$, waterjet pressure $10 \mathrm{MPa}$

(a)

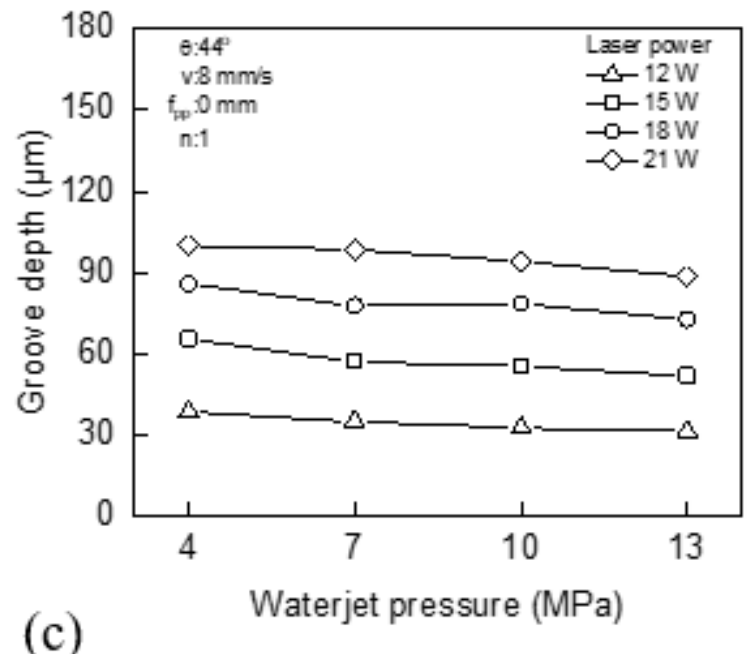

(c)

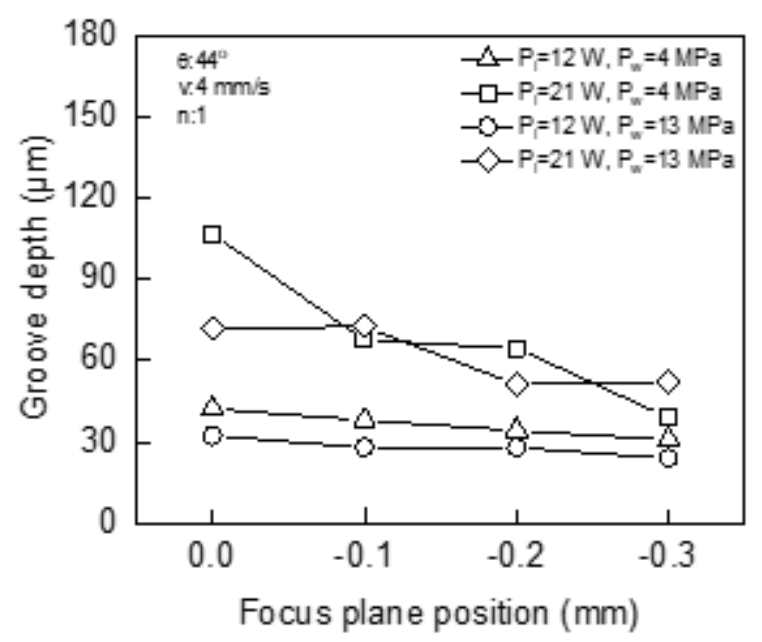

(b)
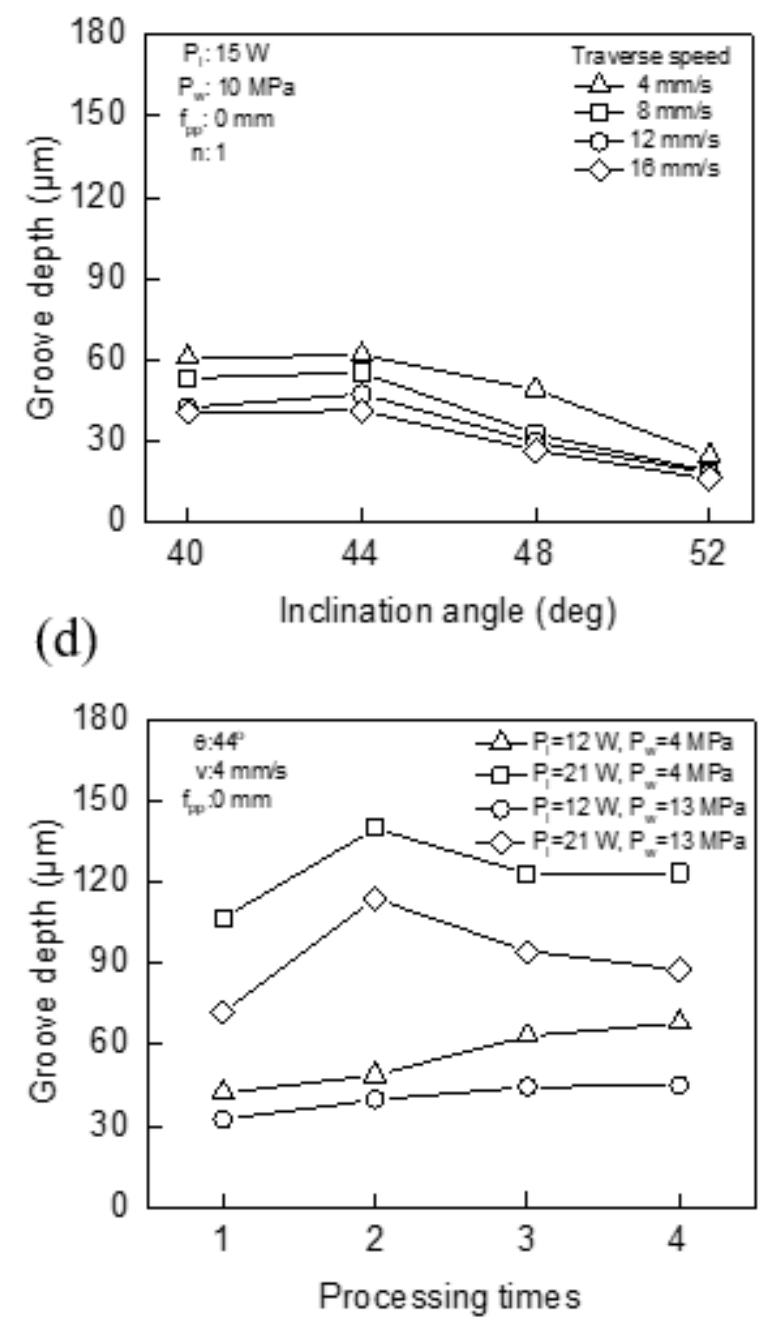

Figure 7

Effect of processing parameters on groove depth 
(a)


703. 6

(c)

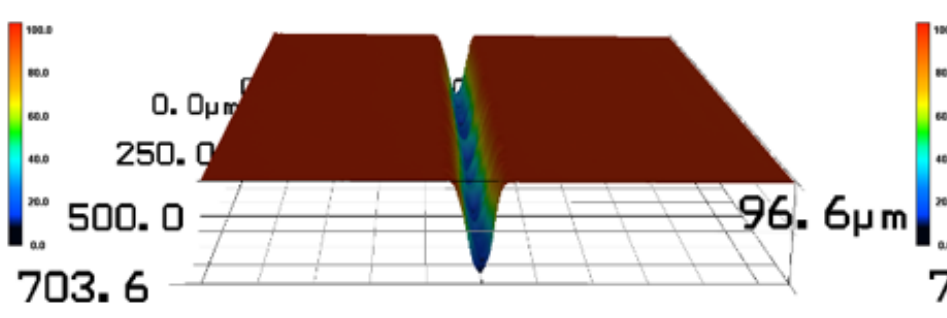

(b)

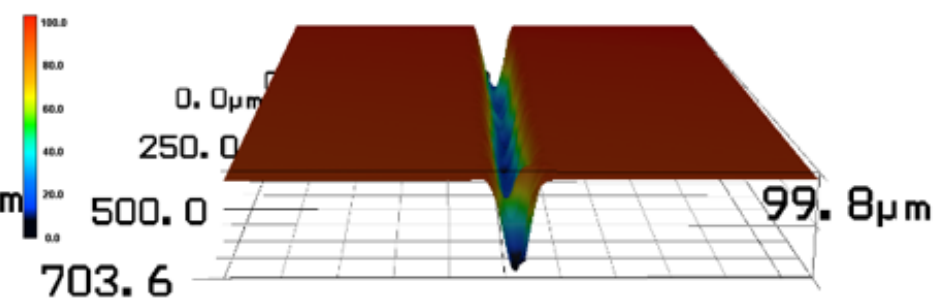

(d)

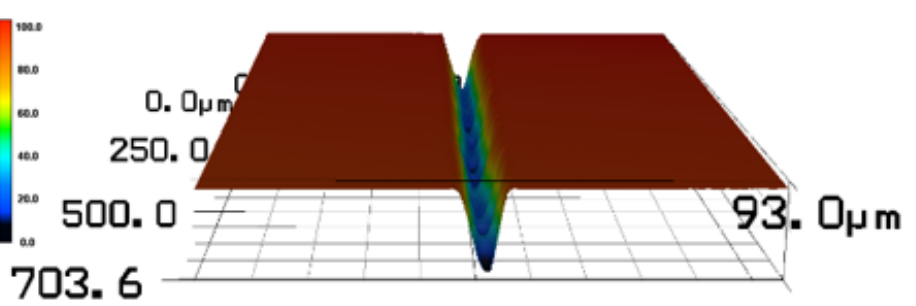

Figure 8

3D views of grooves machined at different waterjet pressure with laser power $18 \mathrm{~W}$. a $4 \mathrm{MPa}, \mathbf{b} 7 \mathrm{MPa}, \mathbf{c}$ $10 \mathrm{MPa}, \mathbf{d} 13 \mathrm{MPa}\left(\theta=44^{\circ}, \mathrm{v}=8 \mathrm{~mm} / \mathrm{s}, \mathrm{fpp}=0 \mathrm{~mm}, \mathrm{n}=1\right)$

(a)

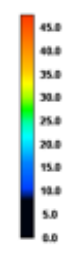
703. 6 (b)

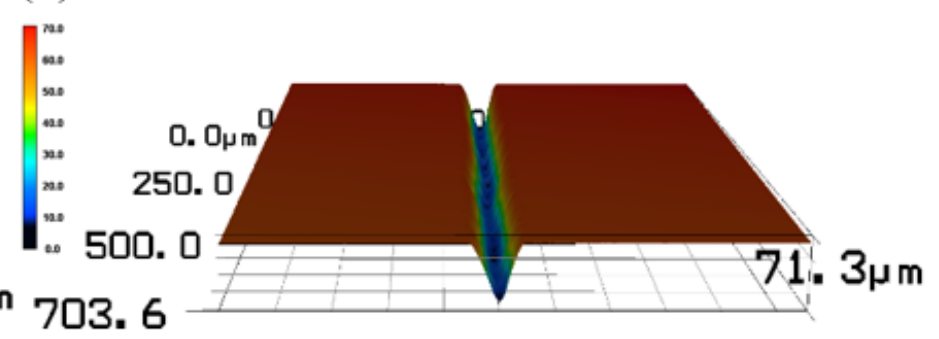

(c)

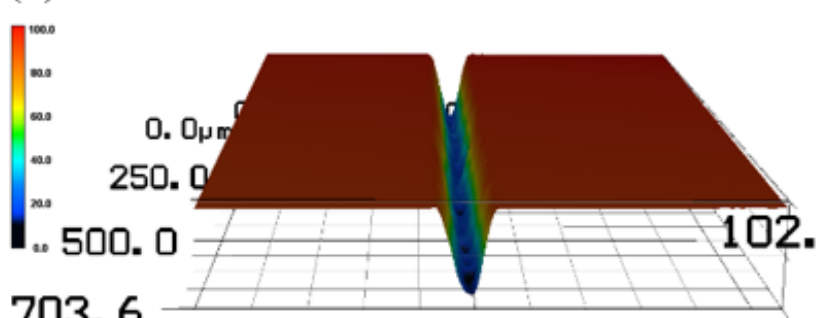

(d)

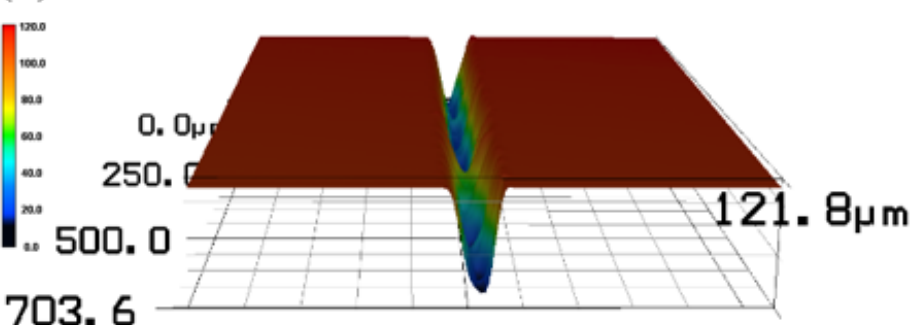

Figure 9

3D views of grooves machined at different laser power with waterjet pressure $10 \mathrm{MPa}$. a $12 \mathrm{~W}, \mathbf{b} 15 \mathrm{~W}, \mathbf{c}$ $18 \mathrm{~W}, \mathrm{~d} 21 \mathrm{~W}\left(\theta=44^{\circ}, \mathrm{v}=8 \mathrm{~mm} / \mathrm{s}, \mathrm{fpp}=0 \mathrm{~mm}, \mathrm{n}=1\right)$ 


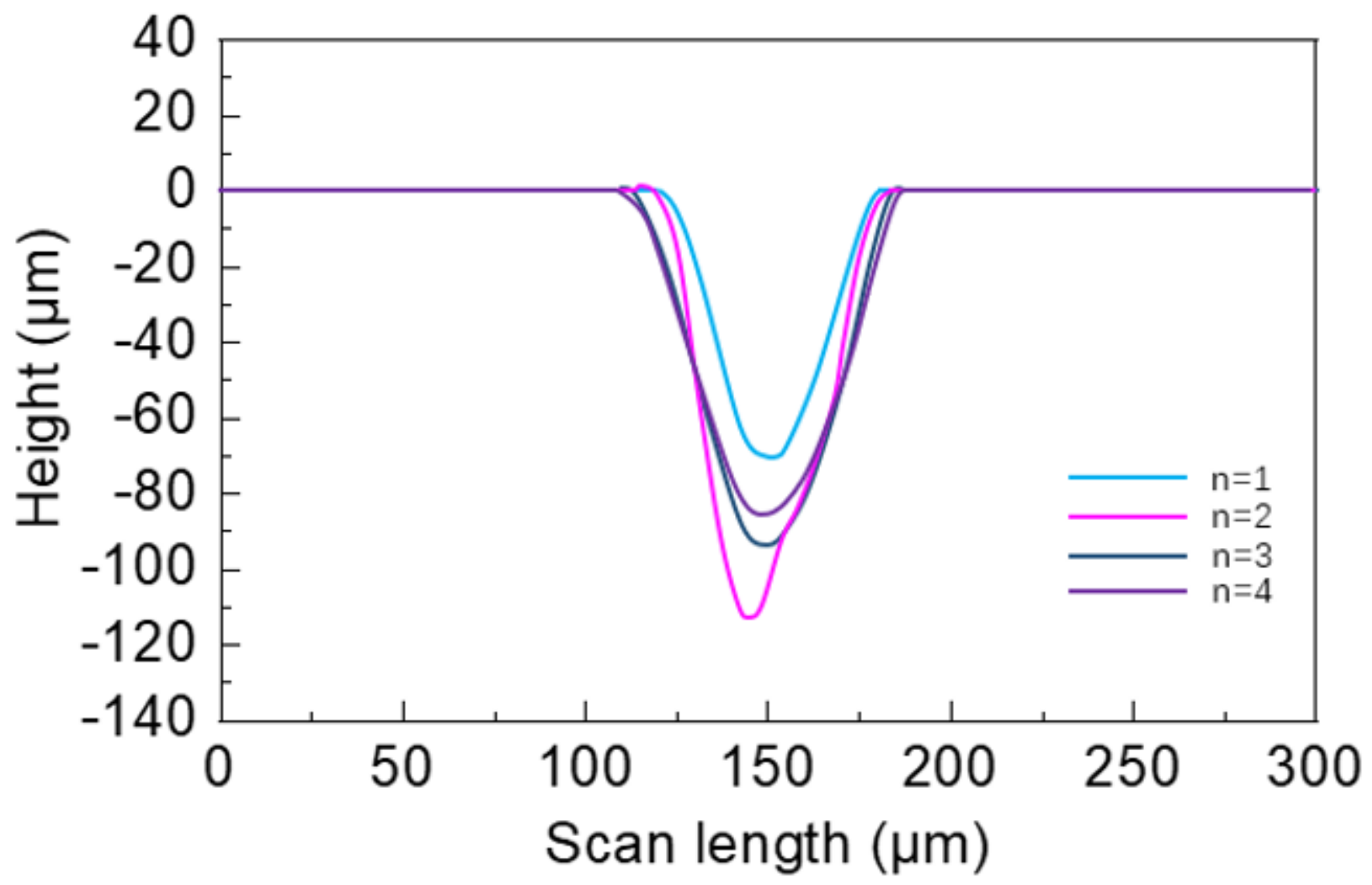

Figure 10

Cross-sectional profiles of grooves machined by different processing times $\left(P_{1}=21 \mathrm{~W}, \mathrm{P}_{\mathrm{W}}=13 \mathrm{MPa}, \theta=\right.$ $44^{\circ}, \mathrm{v}=4 \mathrm{~mm} / \mathrm{s}, \mathrm{fpp}=0 \mathrm{~mm}$ ). 
(a)

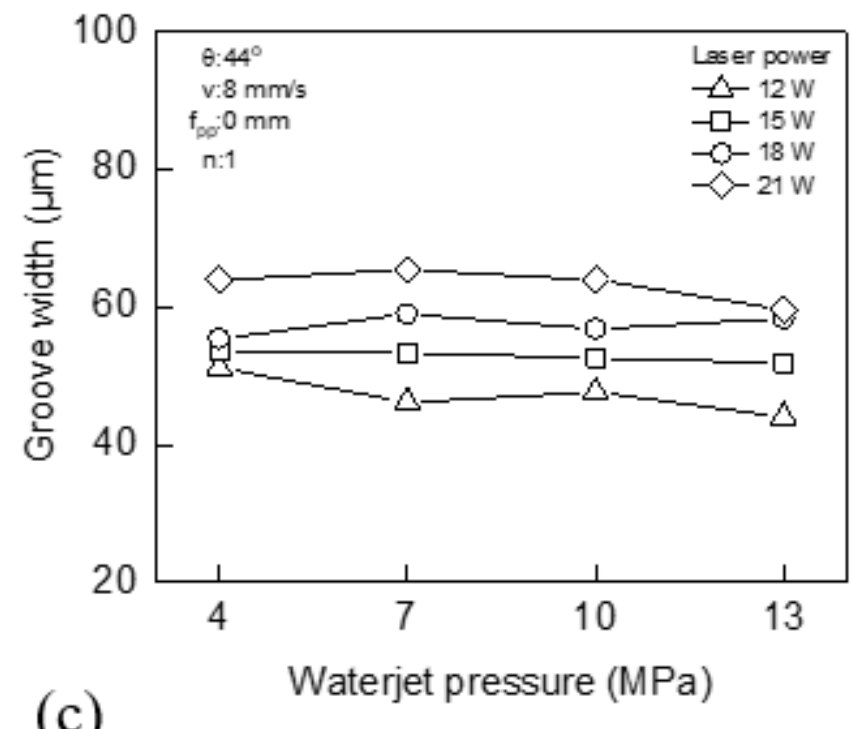

(c)

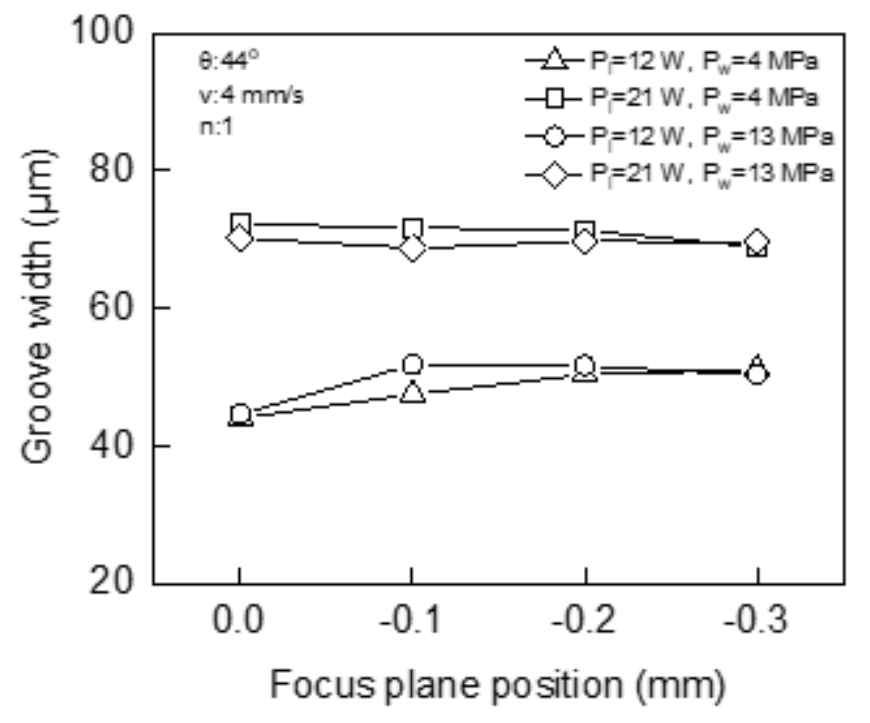

(b)
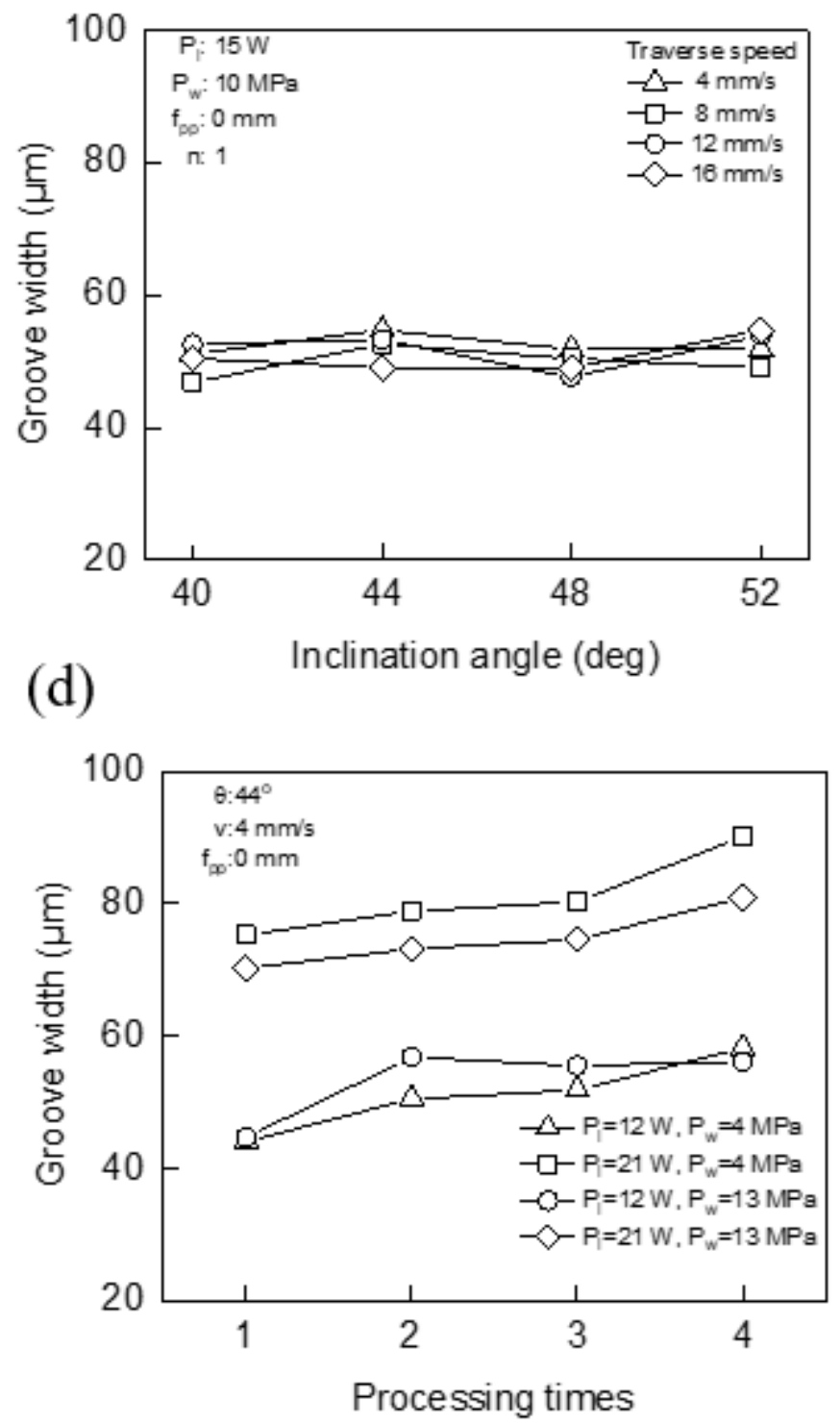

Figure 11

Effect of processing parameters on groove width 


$$
P_{l}=12 \mathrm{~W}
$$

$$
P_{l}=15 \mathrm{~W}
$$

$P_{l}=18 \mathrm{~W}$

$P_{l}=21 \mathrm{~W}$

$P_{w}=13 \mathrm{MPa}$

\section{Figure 12}

Top views of grooves machined at different laser power with waterjet pressure $4 \mathrm{MPa}$ and $13 \mathrm{MPa} .(\theta=$ $44^{\circ}, \mathrm{v}=8 \mathrm{~mm} / \mathrm{s}, \mathrm{fpp}=0 \mathrm{~mm}, \mathrm{n}=1$ )
$\mathrm{v}=4 \mathrm{~mm} / \mathrm{s}$
$\mathrm{v}=8 \mathrm{~mm} / \mathrm{s}$
$\mathrm{v}=12 \mathrm{~mm} / \mathrm{s}$
$\mathrm{v}=16 \mathrm{~mm} / \mathrm{s}$

\section{Figure 13}

Grooves processed with varying traverse speed. $\left(P_{I}=15 \mathrm{~W}, \mathrm{P}_{\mathrm{w}}=10 \mathrm{MPa}\right.$,

$\theta=40^{\circ}, \mathrm{fpp}=0 \mathrm{~mm}, \mathrm{n}=1$ ) 
(a)

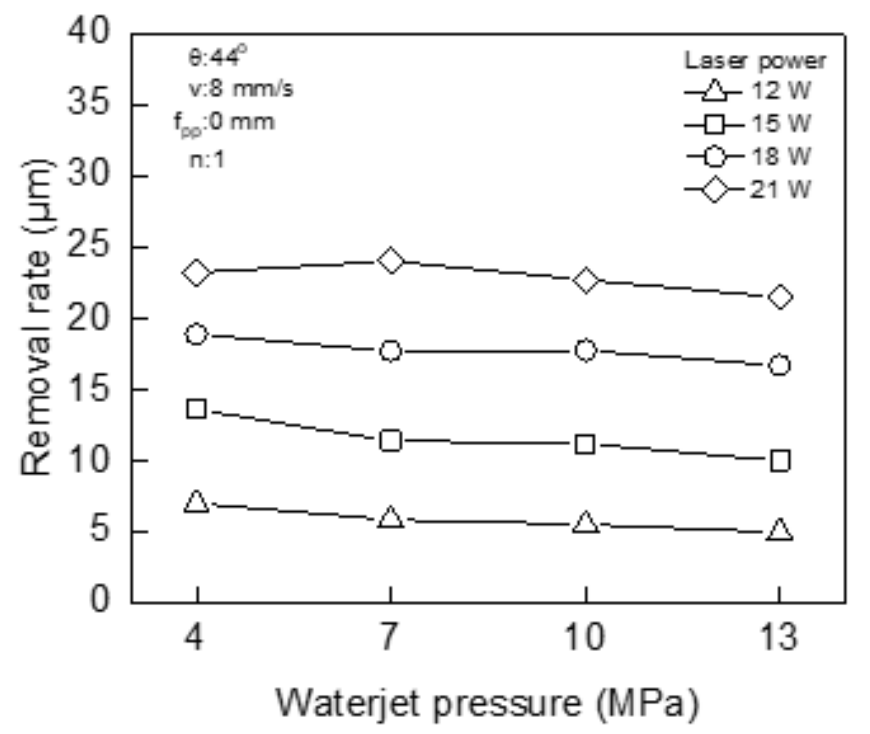

(c) (b)

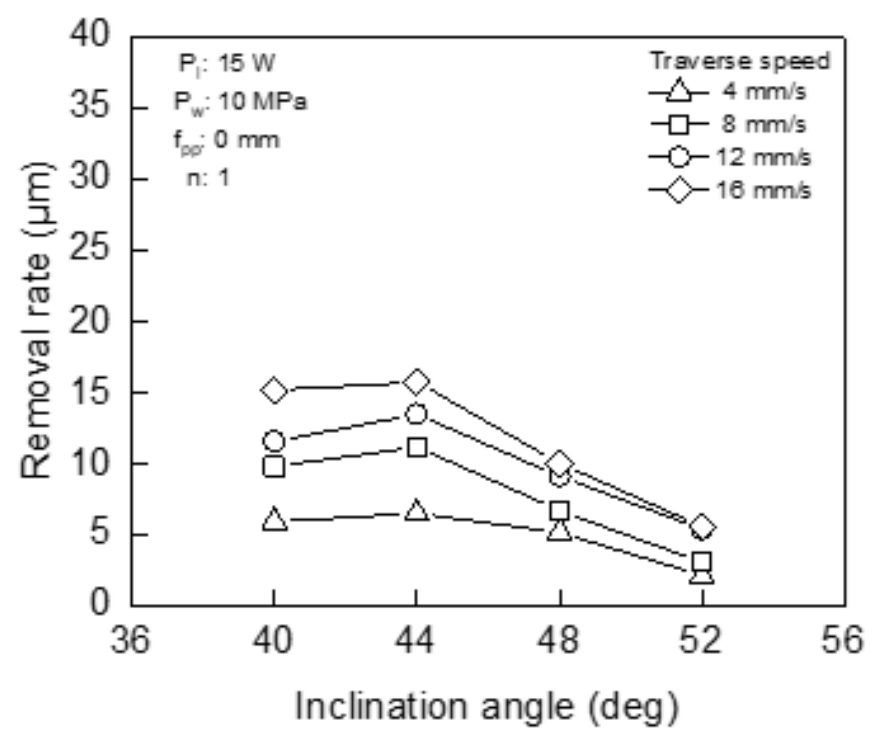

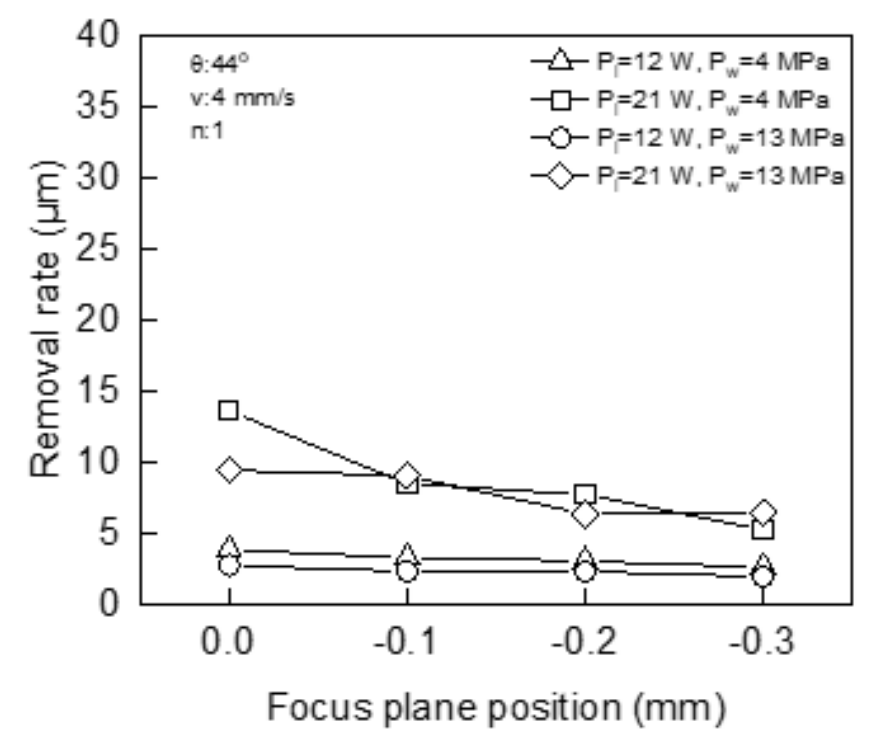

Figure 14

Effect of processing parameters on material removal rate 